\title{
Evaluation of the correlation between effort-reward imbalance and sleep quality among community health workers
}

\author{
Xuexue Deng, Ronghua Fang ${ }^{*}$ (1) and Yaoting Cai
}

\begin{abstract}
Background: A chronic state of imbalance between effort and reward can affect sleep quality. However, few studies have explored the relationship between variables in the work-related stress (the effort-reward imbalance model, ERI model) and sleep quality in community health workers in mainland China. We investigated the relationship between ERI and sleep quality in community health workers.

Methods: This cross-sectional study was conducted from September to November 2018 and involved 249 registered doctors and 223 registered nurses. The Pittsburgh Sleep Quality Index (PSQI) was used to evaluate the sleep problems status of the participants. The ERI questionnaire was administered to evaluate job-related stress. Multivariate logistic regression was performed to evaluate the factors related to sleep quality.

Results: The ERI ratio of the 472 health workers was $1.17 \pm 0.22$, and 273 health workers (57.84\%) had PSQI scores $>7$.There were statistically significant differences in the effort scores, overcommitment scores and ERI ratio between the health workers with and without sleep problems. The ERI ratio was an independent risk factor for sleep quality; sleep quality, race, type of work, shift work,job title, and personal monthly income were related to the ERI ratio among community health workers.

Conclusions: We found that sleep problems were prevalent, work effort was greater than reward and a positive correlation between effort-reward and sleep quality among community health workers in China. Managers should focus on the factors that influence sleep problems among community health workers, balance the efforts and rewards of work, and reduce the incidence of sleep problems.
\end{abstract}

Keywords: Sleep quality, Effort-reward, Community, Health workers

\section{Introduction}

Sleep disorders is a common complaint, and the disorder varies across different populations and age groups [1]. The prevalence of insomnia is high worldwide (26.4$39.4 \%$ in Asian countries; $10-30 \%$ in Western countries) [2-5]. The prevalence of sleep problems is high among health care workers $(30-46 \%$ in the USA; $37-63.9 \%$ in China) [6-9]. Furthermore, many factors, such as

\footnotetext{
* Correspondence: fangronghua@126.com

Department of International Medical Center, West China Hospital/West China School of Nursing, Sichuan University, Chengdu 610041, China
}

sociodemographic and occupational characteristics and occupational risk factors (e.g., shift work and job-related stress), are related to sleep problems [10]. Long-term sleep deprivation may result in serious fatigue, thought retardation, memory loss, slow responses, irritability, depression, suicidal ideation, and occupational accidents $[11,12]$. A previous study revealed that insomnia is a significant risk factor for many chronic diseases, such as diabetes, hypertension, cardiovascular disease, and obesity [13]. Many occupational factors may interfere with sleep, sleep problems can, in turn, endanger the health

(c) The Author(s). 2021 Open Access This article is licensed under a Creative Commons Attribution 4.0 International License, which permits use, sharing, adaptation, distribution and reproduction in any medium or format, as long as you give appropriate credit to the original author(s) and the source, provide a link to the Creative Commons licence, and indicate if changes were made. The images or other third party material in this article are included in the article's Creative Commons licence, unless indicated otherwise in a credit line to the material. If material is not included in the article's Creative Commons licence and your intended use is not permitted by statutory regulation or exceeds the permitted use, you will need to obtain permission directly from the copyright holder. To view a copy of this licence, visit http://creativecommons.org/licenses/by/4.0/ The Creative Commons Public Domain Dedication waiver (http://creativecommons.org/publicdomain/zero/1.0/) applies to the data made available in this article, unless otherwise stated in a credit line to the data. 
and safety of workers [14]. The literature have demonstrated that experiencing job stress enhances the risk of sleep problems. That means, stress can impair sleep, but a low-quality sleep alters the stress response $[15,16]$. The results of the prospective study clearly show a bidirectional relationship between sleep and stress: workers exposed to chronic occupational stress have an increased incidence of sleep problems, and bad sleepers suffer more from occupational stress factors than good sleepers [16]. Therefore, the prevention and control of occupational injuries are challenges for the public health field.

Increasing attention has been given to the development of primary health services in China [17]. Additionally, an imbalance exists in the structural resources. For example, the highest-quality health resources are concentrated in large cities, where Chinese primary health care is still very poor [18]. Most community health workers are busy with basic disease diagnosis and treatment, nursing, chronic disease management, health care for the elderly, maternal health management, child health management, rehabilitation, health education, the management of patients with infectious diseases, and clinical care. These services result in a lack of awareness at the humanistic level and a lack of improvements to medical technology during the service process [19]. However, residents tend to distrust and misunderstand community health care workers, thus affecting the efficiency of work among these professionals, leading to a decline in their sleep quality and a decrease in the safety of their patients [20, 21].

The effort-reward imbalance model proposes similar factors to explain burnout, such as the lack of reciprocity between effort and reward and insufficient levels of respect, esteem, and recognition [22]. The ERI model establishes that workers can feel stress because of an imbalance between perceived effort and reward concerning their work [22]. According to ERI theory, employees expect returns that are aligned with their efforts at work, including income, respect, career development opportunities, and security. The imbalance between effort and reward results in physical and mental impacts, low work efficiency and the dismissal of employees [23, 24]. A chronic state of imbalance between effort and reward can lead to lassitude, anxiety, depression, and other psychological problems that affect sleep quality [24, 25], and also induce metabolic alterations and increase cardiovascular risks [26-28].

Sleep problems have been reported to be prevalent among health workers, and occupational stress can lead to sleep problems [29]. Previous study have suggested that the imbalance between effort and reward may be a direct or an indirect factor leading to poor sleep quality in health workers [30].
In recent years, an increasing number of studies have been conducted on occupational stress and sleep quality. However, to date, few studies have explored the relationship between variables in the ERI model and sleep quality among community health workers in mainland China. Community health workers are more likely to receive lower wages for their efforts [31], which may increase the effort-reward imbalance and decrease sleep quality. The present study investigated the association between sleep quality and ERI among community health workers in mainland China.

\section{Methods}

\section{Study design}

Between September and November 2018, a crosssectional study using questionnaires was performed among health workers in Chengdu, China, to assess mental health. All the participants were health workers who worked at community hospitals in Chengdu, China. Based on a preinvestigation, 20-30 health workers engaged in clinical activities at each community hospital. Twenty community hospitals in Chengdu City with inpatient departments were randomly selected, and 472 health workers were invited to participate in the survey.

The inclusion criteria were as follows: employed at a community hospital with an inpatient department and inpatient beds of 30-40 in the central urban area of Chengdu, had a signed labor contract with a community hospital; had a doctor's/nurse's license; was currently practicing in an inpatient department and providing clinical care; had one or more years of working experience at community hospital [15]. The exclusion criteria were as follows: did not work in inpatient department or provide clinical care; was pregnant or sick or had other personal affairs; had sleep disorder due to alcohol use, disease, or pharmacotherapy; had a family history of sleep disorders; was not willing to participate in the survey.

For data collection, three questionnaires were given to each participant: a questionnaire assessing demographic data, the Effort-Reward Imbalance (ERI) questionnaire, and the Pittsburgh Sleep Quality Index (PSQI) questionnaire. Members of the research team interviewed each participant at their respective work location. The investigator explained the purpose, significance, and relevant instructions for the study and obtained the signed consent form before administering the survey. The questionnaires were provided to the participants electronically through links and quick response codes, and the respondents completed the questionnaires and submitted them online. The data were inputted into EpiData 3.1 software (EpiData Comprehensive Data Management and Basic Statistical Analysis System; EpiData Association, Odense, Denmark) and then were double-checked. 


\section{Demographic data}

This questionnaire was self-designed after a literature review [15]. The participants provided information about their sex, age, race, education background, marital status, chronic illness, type of work, type of contract, work shift, years of work, job title, manager position, personal monthly income and family monthly income.

\section{Effort-reward imbalance}

Studies of occupational stress have considered various theoretical approaches, including the ERI model [23, 24], which emphasizes the nonreciprocal social exchange between costs and gains at work and considers overcommitment, which can cause a state of emotional distress and lead to adverse health outcomes.

The Chinese version of the ERI scale was translated and verified by $\mathrm{Li}$ et al. [32]. The Cronbach's $\alpha$ coefficient of this questionnaire was 0.71 , indicating good reliability and validity [32]. The questionnaire assesses external effort (referring to job demand and job duties; 6 items), rewards (referring to money, respect, and job opportunity; 11 items), and overcommitment (referring to the internal pressure of the individual in the process of work; 6 items). These three factors were scored on a scale from 1 to $4 \quad(1=$ strongly disagree, $4=$ strongly agree). The total score for each component was the sum of the scores for each item; higher scores indicated greater levels of effort/reward/overcommitment [32]. The overall imbalance between effort and reward was obtained using the ERI ratio. The ERI ratio was calculated as [(effort score/reward score) $\times 0.5454]$, where 0.5454 is a correction factor. The correction factor is the ratio of the number of items for effort and rewards and adjusts for unequal items on the subscales. The ERI ratio reflects a perception of imbalance between effort and reward. In particular, an ERI ratio $>1$ indicated that the individual's effort outweighed their reward (i.e., it was stressful), an ERI ratio $=1$ indicated that the effort was equal to the rewards, and an ERI ratio $<1$ indicated that the individual's reward outweighed their effort.

\section{Pittsburgh sleep quality index}

The Chinese version of the PSQI was used to assess subjective sleep quality. The PSQI was developed by Buysse et al. and Liu et al. [33, 34], who translated the index and verified its reliability and validity. The Cronbach's $\alpha$ was 0.845 [33]. The PSQI is a scored 18-item selfreported questionnaire that assesses sleep patterns and sleep quality over the previous month. The 18 questions were grouped into seven clinically derived component scores:sleep quality, sleep latency, sleep duration, habitual sleep efficiency, sleep disturbance, sleep medication usage, and daytime dysfunction. Each component was scored on a Likert-type 4-point scale (0 to 3 ); the components were equally weighted, with higher scores indicating a worse sleep quality. The seven component scores were summed to obtain a global score ranging from 0 to 21. Other researchers have reported that participants with a score of 7 or higher are often considered to have a sleep problem [35]. Thus, in the present study, normal sleep quality was defined as PSQI $\leq 7$, and poor sleep quality was defined as PSQI $>7$.

\section{Statistical analysis}

SPSS software (Version 20.0.; IBM Inc., Armonk, NY) was used for the statistical analyses. Quantitative data, such as the ERI score and PSQI score, were presented as arithmetic means and standard deviation, and betweengroup differences were compared with t-test, analysis of variance, or the nonparametric test. Qualitative data, such as the proportion of participants with a PSQI score $>7$, were represented as percentages. Multivariate regression was used to further analyze the relationship between sleep and effort-reward imbalance and confounding factors were considered in the analysis. Multivariate logistic regression was performed to analyze the influencing factors of sleep quality. The dependent variable was the presence or absence of sleep problems, and the independent variables were the ERI ratio and the demographic characteristic variable which $P>0.2$ was deleted in the model. Multiple linear regression was conducted on the influencing factors of effort-reward imbalance. The ERI ratio was the dependent variable, and the independent variables were with or without sleep problems and the demographic characteristic variable which $P>0.2$ was deleted in the model. The odds ratios and 95\% confidence intervals (CIs) were obtained by logistic regression. A $P$-value $<0.05$ was considered statistically significant.

\section{Results \\ Participants}

The data from 249 doctors and 223 nurses who were community health workers were analyzed. All the completed questionnaires were valid. The rate of validity of the questionnaires for this study was $100 \%$. The ages of the 472 health workers ranged from 18 to 54 years, with an average age of $36.07 \pm 11.31$ years. The sample also had the following characteristics: female, $70.8 \%$; age 25 to 44 years, $72.2 \%$; college or above, $92.6 \%$; married, $86.0 \%$; good health, $86.9 \%$; 5-29 years of work experience, $80.5 \%$; and primary/intermediate doctors or nurses, $78.0 \%$.

Demographic characteristics of the participants, ERI ratios and PSQI scores

The basic characteristics of the participants, ERI ratios and PSQI scores are summarized in Table 1. The overall 
ERI ratio was $1.17 \pm 0.22$; 370 (78.39\%) health workers had occupational stress (ERI ratio $>1$ ), and the scores for the overcommitment dimension were $17.03 \pm 2.28$. The total PSQI score was $8.51 \pm 3.38$, and 273 (57.8\%) health workers had a PSQI $>7$ (median, 7). Statistically significant differences were found in the ERI ratio among community health workers across the following variables: sex, age, education, marital status, chronic illness, type of work, shift work, years of work experience, job title, manager position and personal/family monthly income $(P<0.05)$. Thus, the following factors led to a greater ERI ratio among community health workers: male participants, $35-44$ years of age, bachelor's degree or above, married, chronic illness, doctor, night shift, $10-19$ years of work experience, an intermediate job title, group leader and personal/family monthly income $>10,000$ yuan. Statistically significant differences were observed in the PSQI scores among community health workers across the following variables: sex, chronic illnesses, type of contract, shift work, and years of work experience $(P<0.05)$. Thus, male participants, health workers with chronic diseases, those with authorized strength contracts, those working night shifts and those working $\geq 30$ years had greater PSQI scores. No significant differences were observed in other variables (Table 1).

\section{Comparison between doctors and nurses with different demographic characteristics in ERI and PSQI measures}

There were statistically significant differences between the doctors and nurses in the effort score, reward score, overcommitment score and ERI ratio (Table 2). Additionally, nurses perceived more rewards, less effort and less overcommitment than doctors $(P<0.01)$. Doctors had a higher ERI ratio than nurses $(P=0.001)$. The PSQI scores were similar between the doctors and nurses.

\section{Associations between ERI scale scores and sleep disturbances}

Across the four factors of the ERI, we found that the effort score, overcommitment score, and total ERI ratio were significantly different $(P=0.000$, Table 3$)$ between the health workers with poor sleep quality (PSQI $>7$ ) and those with normal sleep quality (PSQI $\leq 7$ ).

\section{Logistic regression analysis of multiple factors related to sleep quality}

Logistic regression analysis showed that the ERI ratio, type of contract, shift work were the main risk factors for sleep problems in community health workers. Logistic regression analysis was also performed, stratified by type of health worker (doctor and nurse), the ERI ratio was the main risk factor for sleep problems in community doctor or nurse (Table 4).

\section{Linear regression analysis of multiple factors related to the ERI ratio}

The results of linear regression analysis showed that sleep quality, race, type of work, shift work, job title, and personal monthly income were the main factors that affected the ERI ratio among community health workers. Linear regression analysis was also performed, stratified by type of health worker (doctor and nurse), sleep quality, shift work and job title were the main factors that affected the ERI ratio for community doctors; sleep quality, shift work and personal monthly income were the main factors for community nurses (Table 5).

\section{Discussion}

The present study showed that sleep problems were prevalent among community health workers in China. Additionally, we found a higher risk of sleep problem among male participants, those with chronic illness, those with authorized strength contracts, those who worked night shifts, and those who had worked $\geq 30$ years. More importantly, the study indicated that, as the health workers' ERI ratios increased, sleep quality progressively worsened (Table 1), indicating that job stress affects the sleep quality of health workers $[6,8,35]$.

Our research showed that community doctors perceived higher levels of effort and overcommitment and lower levels of rewards than community nurses. This finding is inconsistent with other study findings [36, 37]. The reward score comprises three components: financial and career-related aspects, esteem-related rewards, and the gratification of job security [24]. As the primary providers of health services, doctors have a heavy burden. Some general practitioners (GPs) came from general hospitals, and they were exposed to several factors that are inferior to those of general hospitals, such as work overload, time pressures, role conflicts, lower compensation and fewer career development opportunities. Promotions and other normal conditions also limit GP development and effort-reward imbalances; thus, they encounter more job stress than nurses, and their job satisfaction is not high. In contrast, the jobs of nurses are relatively clear in the community; thus, their job satisfaction is higher than that of GPs [31,38]. Regardless of the unsafe clinical environment, health workers are always committed to providing timely health services without hesitation or reservations in China, contributing to the imbalance between effort and reward and leading to higher job stress $[39,40]$. Our results showed that the ERI ratio of community health workers was $1.17 \pm 0.22$, indicating that community health workers generally perceived more effort than rewards. We found a higher ERI ratio among those with the following demographic characteristics: males, 35-44 years, bachelor's degree or above, married, chronic illness, doctors, worked night 
Table 1 Demographic characteristics of the participants and total scores for the PSQI and ERI

\begin{tabular}{|c|c|c|c|c|c|c|c|}
\hline & $N(\%)$ & PSQI score & $t / F$ & $P$ & ERI ratio & $t / F$ & $P$ \\
\hline Sex & & & 6.233 & 0.013 & & 9.968 & 0.002 \\
\hline Male & $138(29.2)$ & $9.11 \pm 3.67$ & & & $1.21 \pm 0.24$ & & \\
\hline Female & $334(70.8)$ & $8.26 \pm 3.22$ & & & $1.15 \pm 0.21$ & & \\
\hline Age range, $y$ & & & 2.476 & 0.061 & & 11.458 & 0.000 \\
\hline $18-24$ & $42(8.9)$ & $7.21 \pm 2.91$ & & & $1.03 \pm 0.18$ & & \\
\hline $25-34$ & $164(34.7)$ & $8.48 \pm 3.38$ & & & $1.14 \pm 0.20$ & & \\
\hline $35-44$ & $177(37.5)$ & $8.70 \pm 3.32$ & & & $1.23 \pm 0.23$ & & \\
\hline $45-54$ & 89 (18.9) & $8.79 \pm 3.59$ & & & $1.16 \pm 0.20$ & & \\
\hline Race & & & 0.334 & 0.564 & & 3.621 & 0.058 \\
\hline Ethnic Han & $453(96.00)$ & $8.49 \pm 3.40$ & & & $1.17 \pm 0.22$ & & \\
\hline Others & $19(4.00)$ & $8.94 \pm 2.71$ & & & $1.07 \pm 0.28$ & & \\
\hline Education & & & 1.380 & 0.253 & & 11.489 & 0.000 \\
\hline Polytechnic school & $35(7.4)$ & $8.14 \pm 3.61$ & & & $1.09 \pm 0.13$ & & \\
\hline College & $228(48.3)$ & $8.30 \pm 3.33$ & & & $1.13 \pm 0.21$ & & \\
\hline Bachelor's degree or above & $209(44.3)$ & $8.79 \pm 3.37$ & & & $1.22 \pm 0.23$ & & \\
\hline Marital status & & & 3.907 & 0.452 & & 3.087 & 0.002 \\
\hline Married & $406(86.0)$ & $8.55 \pm 3.46$ & & & $1.18 \pm 0.22$ & & \\
\hline Single & $66(24.0)$ & $8.26 \pm 2.81$ & & & $1.10 \pm 0.17$ & & \\
\hline Chronic illness & & & 7.748 & 0.006 & & 5.991 & 0.015 \\
\hline Yes & $62(13.1)$ & $9.61 \pm 3.51$ & & & $1.23 \pm 0.19$ & & \\
\hline No & $410(86.9)$ & $8.34 \pm 3.33$ & & & $1.16 \pm 0.22$ & & \\
\hline Type of work & & & 3.717 & 0.054 & & 28.627 & 0.000 \\
\hline Doctor & $249(52.8)$ & $8.79 \pm 3.48$ & & & $1.22 \pm 0.24$ & & \\
\hline Nurse & $223(47.2)$ & $8.19 \pm 3.24$ & & & $1.11 \pm 0.18$ & & \\
\hline Type of contract & & & 3.937 & 0.020 & & 2.766 & 0.064 \\
\hline Long-term contract & $186(39.4)$ & $8.21 \pm 3.21$ & & & $1.14 \pm 0.21$ & & \\
\hline Permanent contract & $39(8.3)$ & $7.54 \pm 3.02$ & & & $1.13 \pm 0.19$ & & \\
\hline Authorized strength & $247(52.3)$ & $8.89 \pm 3.51$ & & & $1.19 \pm 0.23$ & & \\
\hline Shift work & & & 9.862 & 0.002 & & 29.256 & 0.000 \\
\hline Day shift & $327(69.3)$ & $8.19 \pm 3.33$ & & & $1.13 \pm 0.21$ & & \\
\hline Night shift & $145(30.7)$ & $9.23 \pm 3.39$ & & & $1.25 \pm 0.22$ & & \\
\hline Years of work experience & & & 4.810 & 0.001 & & 8.341 & 0.000 \\
\hline$<5$ & 65 (13.8) & $6.92 \pm 2.86$ & & & $1.03 \pm 0.20$ & & \\
\hline $5-9$ & $127(26.9)$ & $8.90 \pm 3.52$ & & & $1.18 \pm 0.20$ & & \\
\hline $10-19$ & $150(31.8)$ & $8.81 \pm 3.10$ & & & $1.21 \pm 0.22$ & & \\
\hline $20-29$ & $103(21.8)$ & $8.40 \pm 3.55$ & & & $1.18 \pm 0.23$ & & \\
\hline$\geq 30$ & $27(5.7)$ & $9.26 \pm 3.69$ & & & $1.14 \pm 0.15$ & & \\
\hline Job title & & & 2.268 & 0.080 & & 12.587 & 0.000 \\
\hline Registered & $39(8.3)$ & $7.49 \pm 3.25$ & & & $1.05 \pm 0.18$ & & \\
\hline Primary & $225(47.7)$ & $8.34 \pm 3.36$ & & & $1.13 \pm 0.21$ & & \\
\hline Intermediate & $143(30.3)$ & $8.86 \pm 3.39$ & & & $1.23 \pm 0.22$ & & \\
\hline Subsenior & 65 (13.8) & $8.94 \pm 3.37$ & & & $1.22 \pm 0.24$ & & \\
\hline Manager position & & & 2.164 & 0.116 & & 6.483 & 0.002 \\
\hline No & $314(66.5)$ & $8.28 \pm 3.34$ & & & $1.14 \pm 0.21$ & & \\
\hline
\end{tabular}


Table 1 Demographic characteristics of the participants and total scores for the PSQI and ERI (Continued)

\begin{tabular}{|c|c|c|c|c|c|c|c|}
\hline & $N(\%)$ & PSQI score & $t / F$ & $P$ & ERI ratio & $t / F$ & $P$ \\
\hline Group leader & $38(8.1)$ & $8.89 \pm 3.62$ & & & $1.23 \pm 0.22$ & & \\
\hline Director/Head doctor, nurse & $120(25.4)$ & $8.98 \pm 3.36$ & & & $1.21 \pm 0.23$ & & \\
\hline Personal monthly income, yuan & & & 1.542 & 0.189 & & 7.073 & 0.000 \\
\hline$\leq 3000$ & $59(12.5)$ & $7.73 \pm 3.86$ & & & $1.07 \pm 0.22$ & & \\
\hline $3001-5000$ & $197(41.7)$ & $8.64 \pm 3.21$ & & & $1.14 \pm 0.21$ & & \\
\hline $5001-8000$ & $165(35.0)$ & $8.80 \pm 3.42$ & & & $1.21 \pm 0.22$ & & \\
\hline $8001-10,000$ & $36(7.6)$ & $7.94 \pm 3.20$ & & & $1.21 \pm 0.19$ & & \\
\hline$>10,000$ & $15(3.2)$ & $7.93 \pm 3.17$ & & & $1.29 \pm 0.17$ & & \\
\hline Family monthly income, yuan & & & 0.335 & 0.854 & & 2.688 & 0.031 \\
\hline$\leq 3000$ & $52(11.0)$ & $8.60 \pm 3.67$ & & & $1.13 \pm 0.22$ & & \\
\hline $3001-5000$ & $129(27.3)$ & $8.77 \pm 3.36$ & & & $1.18 \pm 0.22$ & & \\
\hline $5001-8000$ & $112(23.7)$ & $8.46 \pm 3.13$ & & & $1.16 \pm 0.23$ & & \\
\hline $8001-10,000$ & $90(19.1)$ & $8.32 \pm 3.40$ & & & $1.12 \pm 0.18$ & & \\
\hline$>10,000$ & 89 (18.9) & $8.33 \pm 3.53$ & & & $1.21 \pm 0.22$ & & \\
\hline
\end{tabular}

shifts, working $\geq 30$ years, intermediate job title, group leader, and monthly income $>10,000$ yuan. This finding is consistent with other study findings [41, 42]; the occupational task and stress response for the male participants were higher than those for the female participants and higher in those with a high education level than in those with a low education level. The scores on the overcommitment dimension were $17.03 \pm 2.28$, which was higher than that reported in previous studies [42, 43]. Inadequate compensation is a concept incorporated into the ERI model: high effort and low compensation lead to high stress [35]. In the present study, 370 (78.39\%) health workers had a high ERI (ERI ratio $>1$ ), which was associated with sleep problem,consistent with previous study [44]. Another research has suggested that a high ERI ratio (versus low ERI) is associated with poorer psychosocial care and even more errors [45]. Moreover, many previous studies have shown that effort-reward imbalance can lead to adverse health outcomes [33, 46].

With health system reforms, the connotation and work volume of community health workers have continuously increased, and occupational stress will inevitably increase.

Table 2 Comparison of the ERI and PSQI measures between doctors and nurses

\begin{tabular}{lllll}
\hline Characteristics & $\begin{array}{l}\text { Doctors } \\
\text { M } \pm \text { SD }\end{array}$ & $\begin{array}{l}\text { Nurses } \\
\mathbf{M} \pm \text { SD }\end{array}$ & $\boldsymbol{t}$ & $\boldsymbol{P}$ \\
\hline Effort (scores) & $19.31 \pm 3.34$ & $18.19 \pm 3.03$ & 14.427 & 0.000 \\
Reward (scores) & $29.37 \pm 2.93$ & $30.09 \pm 2.39$ & 8.451 & 0.004 \\
Overcommitment (scores) & $17.28 \pm 2.30$ & $16.75 \pm 2.23$ & 6.472 & 0.011 \\
ERI ratio & $1.22 \pm 0.24$ & $1.11 \pm 0.18$ & 28.627 & 0.000 \\
PSQl scores & $8.79 \pm 3.48$ & $8.19 \pm 3.24$ & 3.717 & 0.054 \\
\hline
\end{tabular}

The participants in the present study had higher levels of occupational stress, likely because the study was conducted in southwestern China, which is less economically developed; thus, the rewards for community health workers are far lower than those in coastal areas. Additionally, doctor-patient relationships are becoming increasingly fragile in China [47]. Using doctor-patient relationships to evaluate the costs and rewards of a doctor's professional and emotional investment is unfair because these fragile relationships result in resource depletion, which is closely related to job stress, burnout and depression in health workers [48]. Therefore, managers should adopt measures to reduce the incidence of occupational stress among health workers at community hospitals.

Health workers with poor sleep quality had higher levels of perceived effort, higher levels of perceived overcommitment, and higher ERI ratios than those with good sleep quality (Table 3). This finding is consistent with existing study findings [49]. Table 4 shows that the ERI ratio is the main risk factor for sleep disturbances in community health workers, and the same result was found for doctors and nurses. Overall, $78.39 \%$ of health workers had occupational stress (ERI ratio $>1$ ), higher than that reported by Ge et al. (64.7\%) [50]. This result can be explained by China's national conditions and work characteristics of the community health sector. In China, the need for health services is increasing with the development of the economy, particularly at community hospitals [15], and the nature of psychosocial work environments varies considerably between hospitals and primary care [51]. Community health workers are generally considered less competent than those at general hospitals, not only doctors but also nurses; this situation 
Table 3 ERI factors and sleep disturbances

\begin{tabular}{|c|c|c|c|c|}
\hline & Nonsufferers ${ }^{A}$ (Mean \pm SD) & Sufferers $^{B}($ Mean \pm SD $)$ & $t$ & $P$ \\
\hline Effort (scores) & $17.32 \pm 3.00$ & $19.84 \pm 3.00$ & -9.013 & 0.000 \\
\hline Reward (scores) & $29.46 \pm 2.49$ & $29.89 \pm 2.84$ & -1.741 & 0.082 \\
\hline Overcommitment (scores) & $15.88 \pm 2.06$ & $17.86 \pm 2.07$ & -10.292 & 0.000 \\
\hline ERI ratio & $1.08 \pm 0.20$ & $1.22 \pm 0.21$ & -7.496 & 0.000 \\
\hline
\end{tabular}

${ }^{\mathrm{A}}$ Nonsufferers indicate those with PSQI scores $\leq 7 ;{ }^{\mathrm{B}}$ sufferers indicate those with PSQI scores $>7$

requires community health workers to expend more effort to earn respect from ordinary people and achieve overall organizational goals. The study showed that overcommitment among community health workers was high, indicating that they might overestimate their capabilities and play more effort into finishing work that is beyond their abilities [50].

Further analysis indicated that sleep quality, race, type of work, shift work, job title and personal monthly income were the main risk factors for a higher ERI ratio in community health workers, but a difference was observed between doctors and nurses (Table 5). Sleep quality and shift work were the same risk factors for a higher ERI ratio for doctors and nurses. The difference is likely due to the work characteristics of community doctors and nurses. Night nurses are under more job stress than night doctors, but nurses are paid far less than doctors. A previous study recognized that shift work could affect not only nurses' personal health but also the quality of their work and their patients' psychological health and treatment, even result in mistakes and accidents [52]. Previous studies showed that reward (rather than effort) is a strong determinant of employees' job satisfaction and quality of care [53, 54]. Community doctors are under a high-stress occupation, lack promotion and learning opportunities, decreasing their job satisfaction. Another study showed that high levels of satisfaction with the nature of one's work positively affected physical and mental health [55]. If the efforts and rewards at work cannot be balanced, professionals will find their jobs difficult, causing occupational stress and affecting sleep quality. Overcommitment and effort-reward imbalance have been identified as important occupational stress factors that negatively contribute to the psychological and physical health and wellbeing of employees [56].

This study confirmed the hypothesized bidirectional forward associations between sleep and stress: community health workers exposed to chronic job stress have an increased incidence of sleep problems. This results are similar observations from the Swedish Longitudinal Occupational Survey of Health [57]. In fact, being a cross-sectional study, no one can tell whether workers had job stress first, or sleep problems first. Our sample is slightly less homogeneous, although the work performed by community health workers are basically the same, they still have different tasks, some with night work, some without, some managerial, some not. The study results may not be possible to generalize the findings to other cultures and geographic regions in China.

Community health workers report higher levels of ERI, resulting in occupational stress, which leads to sleep problems and diseases. Therefore, organizational

Table 4 Logistic regression analysis of factors related to sleep quality

\begin{tabular}{|c|c|c|c|c|c|}
\hline Model & Independent variable & $\beta$ & Wald & $P$ & OR $(95 \% \mathrm{Cl})$ \\
\hline \multirow[t]{6}{*}{ Model $1^{\mathrm{A}}$} & ERI ratio & -1.289 & 6.546 & 0.011 & $0.275(0.103,0.740)$ \\
\hline & Type of contract & & 6.375 & 0.041 & \\
\hline & Permanent contract & 0.887 & 6.133 & 0.013 & $2.249(1.203,4.903)$ \\
\hline & Authorized strength & 0.666 & 3.346 & 0.067 & $1.946(0.954,3.970)$ \\
\hline & Shift work & 0.482 & 5.162 & 0.023 & $1.619(1.068,2.454)$ \\
\hline & Constant & 1.478 & 1.091 & 0.175 & \\
\hline \multirow[t]{2}{*}{ Model $2^{B}$} & ERI ratio & -1.025 & 3.916 & 0.048 & $0.359(0.130,0.990)$ \\
\hline & Constant & 2.412 & 5.710 & 0.017 & \\
\hline \multirow[t]{2}{*}{ Model $3^{c}$} & ERI ratio & 0.997 & 9.941 & 0.002 & $2.711(1.458,5.308)$ \\
\hline & Constant & -1.654 & 7.546 & 0.006 & \\
\hline
\end{tabular}

A Logistic regression analysis of factors related to the sleep quality of health workers. ${ }^{\mathrm{B}}$ Logistic regression analysis of factors related to the sleep quality of doctors. CLogistic regression analysis of factors related to the sleep quality of nurses 
Table 5 Linear regression analysis of factors related to the ERI ratio

\begin{tabular}{|c|c|c|c|c|c|c|}
\hline \multirow[t]{2}{*}{ Model } & \multirow[t]{2}{*}{ Independent variable } & \multicolumn{2}{|c|}{ Unstandardized Coefficients } & \multirow{2}{*}{$\begin{array}{l}\text { standardized } \\
\text { regression } \\
\text { coefficient }\end{array}$} & \multirow[t]{2}{*}{$\mathbf{t}$} & \multirow[t]{2}{*}{$P$} \\
\hline & & $\beta$ & standard error & & & \\
\hline \multirow[t]{7}{*}{ Model $1^{\mathrm{A}}$} & Constant & 0.902 & 0.075 & & 12.073 & 0.000 \\
\hline & Sleep quality & 0.122 & 0.018 & 0.274 & 6.727 & 0.000 \\
\hline & Race & -0.108 & 0.045 & -0.097 & -2.405 & 0.017 \\
\hline & Type of work & -0.079 & 0.018 & -0.180 & -4.419 & 0.000 \\
\hline & Shift work & 0.097 & 0.019 & 0.205 & 5.013 & 0.000 \\
\hline & Job title & 0.045 & 0.017 & 0.128 & 2.734 & 0.007 \\
\hline & Personal monthly income & 0.025 & 0.011 & 0.104 & 2.303 & 0.022 \\
\hline \multirow[t]{4}{*}{ Model $2^{B}$} & Constant & 0.622 & 0.069 & & 9.407 & 0.000 \\
\hline & Sleep quality & 0.150 & 0.027 & 0.306 & 5.467 & 0.000 \\
\hline & Shift work & 0.103 & 0.028 & 0.202 & 3.625 & 0.000 \\
\hline & Job title & 0.083 & 0.016 & 0.285 & 5.105 & 0.000 \\
\hline \multirow[t]{4}{*}{ Model $3^{C}$} & Constant & 0.746 & 0.053 & & 14.047 & 0.000 \\
\hline & Sleep quality & 0.083 & 0.022 & 0.232 & 3.730 & 0.000 \\
\hline & Shift work & 0.094 & 0.025 & 0.236 & 3.798 & 0.000 \\
\hline & Personal monthly income & 0.051 & 0.013 & 0.236 & 3.904 & 0.000 \\
\hline
\end{tabular}

${ }^{\mathrm{A}}$ Linear regression analysis of factors related to the ERI ratio of health workers. ${ }^{\mathrm{B}}$ Linear regression analysis of factors related to the ERI ratio of doctors. ${ }^{\mathrm{C}}$ Linear regression analysis of factors related to the ERI ratio of nurses

interventions, such as increasing rewards and improving doctor-patient relationships, should be considered in China.

This study had several limitations that may have affected the outcomes. The main limitation of our study is convenience sample, but not having a randomized sampling method resulting a small sample size if we consider that we are referring to Chinese community workers, at the same time the lack of a control group limits the generalization of the results. Another limitation is assessing community health workers for serious sleep problems and comparing the results across individuals with different professional functions should be performed.

\section{Conclusions}

We found that sleep problems were prevalent among health workers at community hospitals in Southwest China. The main risk factors for sleep disturbances in health workers was ERI ratio. The ERI affects sleep quality in Chinese community health workers, such that higher ERI ratios lead to a worse sleep quality. Sleep disturbances may lead to a lower quality of life and lower work efficiency levels for health workers, increasing the potential for errors or medical malpractice. Therefore, awareness and interventions are required to reduce job stress at community hospitals. Additional research on this topic is also required.

Abbreviations

PSQI: Pittsburgh Sleep Quality Index; ERI: Effort-Reward Imbalance
Acknowledgements

We are grateful to all doctors and nurses who participated in the study.

\section{Authors' contributions}

FR carried out conceptualization, project administration and supervision. DX and $C Y$ performed investigation and prepared the original draft. DX analyzed and interpreted data. FR and DX reviewed and edited the manuscript. All

authors read and approved the final manuscript.

\section{Funding}

1. West China nursing discipline development special fund project, Sichuan University, China, NO:HXHL19021.

2. Science and technology department of Sichuan Province, China, NO: 2020YFS0151.

Availability of data and materials

The datasets used and analysed during the current study are available from the corresponding author on reasonable request.

\section{Declarations}

Ethics approval and consent to participate

The ethics committee of West China Hospital of Sichuan University approved this study and its methods in August 2017 (approve number 2017(46)). All participants provided signed informed consent.

Consent for publication

Not applicable.

Competing interests

The authors declare that they have no competing interests.

Received: 25 November 2020 Accepted: 13 May 2021

Published online: 22 May 2021

References

1. Dregan A, Armstrong D. Cross-country variation in sleep disturbance among working and older age groups: an analysis based on the European social 
survey. Int Psychogeriatr. 2011;23(9):1413-20. https://doi.org/10.1017/S1041 610211000664.

2. Wong WS, Fielding R. Prevalence of insomnia among Chinese adults in Hong Kong: a population-based study. J Sleep Res. 2011;20(1pt1):117-26. https://doi.org/10.1111/j.1365-2869.2010.00822.x.

3. Ahn D-H. Insomnia: causes and diagnosis. Hanyang Med Rev. 2013;33(4): 203-9. https://doi.org/10.7599/hmr.2013.33.4.203.

4. Luckhaupt SE, Tak S, Calvert GM. The prevalence of short sleep duration by industry and occupation in the National Health Interview Survey. Sleep. 2010;33(2):149-59. https://doi.org/10.1093/sleep/33.2.149.

5. Siwoo L, Jin HJ. Domestic trends of research and patent for sleep disorder. J Korea Contents Assoc. 2013;13:309-17.

6. Yuan Z, Laura P, Sc D, Geoffry PM, Rebecca G. Contributing influences of work environment on sleep quantity and quality of nursing assistants in long-term care facilities: A cross-sectional study. Geriatr Nurs. 2016;37:13-8.

7. Ghalichi L, Pournik $\mathrm{O}$, Ghaffari M, Vingard E. Sleep quality among health care workers. Arch Iran Med. 2013;16:100-3.

8. Dong H, Zhang Q, Sun Z, Sang F, Xu Y. Sleep disturbances among Chinese clinical nurses in general hospitals and its influencing factors. BMC Psychiatr. 2017;17(1):241. https://doi.org/10.1186/s12888-017-1402-3.

9. Han $Y$, Yuan $Y$, Zhang L, Fu Y. Sleep disorder status of nurses in general hospitals and its influencing factors. Psychiatr Danub. 2016; 28(2):176-83.

10. Liu XL, Deng XX, Li RQ, Fang RH. Analysis of influencing factors on sleep quality of community health workes. Guangxi Med J. 2018; 40: 2020-2023. [Chinese].

11. Mieda M, Sakurai T. Orexin (hypocretin) receptor agonists and antagonists for treatment of $\mathrm{s}$. rationale for development and current status. CNS Drugs. 2013;27(2):83-90. https://doi.org/10.1007/s40263-012-0036-8.

12. Rosado IV, Russo GH, Maia EM. Generating health elicits illness? The contradictions of work performed in emergency care units of public hospitals. Cien Saude Colet. 2015;20(10):3021-32. https://doi.org/10.1 590/1413-812320152010.13202014.

13. Salminen $S$, Oksanen T, Vahtera J, Sallinen M, Härmä M, Salo P, et al. Sleep disturbances as a predictor of occupational injuries among public sector workers. J Sleep Res. 2010;19(1p2):207-13. https://doi.org/10.1111/j.1365-2 869.2009.00780.x.

14. Magnavita N, Garbarino S. Sleep, Health and Wellness at Work: A Scoping Review. Int J Environ Res Public Health. 2017;14(11):1347.

15. Deng $X$, Liu $X$, Fang R. Evaluation of the correlation between job stress and sleep quality in community nurses. Medicine (Baltimore). 2020;99(4):e18822. https://doi.org/10.1097/MD.0000000000018822.

16. Garbarino S, Magnavita N. Sleep problemss are a strong predictor of stressrelated metabolic changes in police officers. A prospective study. PLoS One. 2019;14(10):e0224259.

17. Itani $\mathrm{O}$, Jike M, Watanabe $\mathrm{N}$, Kaneita Y. Short sleep duration and health outcomes: a systematic review, meta-analysis, and meta-regression. Sleep Med. 2017;32:246-56. https://doi.org/10.1016/.sleep.2016.08.006.

18. Alex JH, Qingyue M. An interim interdisciplinary evaluation of China's national health care reform: emerging evidence and new perspectives. J Asian Public Policy. 2015;8:1-18.

19. Sun T, Gao L, Li F, Shi Y, Xie F, Wang J, et al. Workplace violence, psychological stress, sleep quality and subjective health in Chinese doctors: a large cross sectional study. BMJ Open. 2017;7:1-8.

20. Liu G, Zhang Z, Ma C, Huang R, Feng Z. Investigation and analysis of clinical doctors'humanity quality. Chin Hosp Manag. 2012;32:17-9.

21. Yoshizawa K, Sugawara N, Yasui-Furukori N, Danjo K, Furukori H, Sato Y, et al. Relationship between occupational stress and depression among psychiatric nurses in Japan. Arch Environ Occup Health. 2016;71(1):10-5. https://doi.org/10.1080/19338244.2014.927345.

22. Zhang Q, Yang L, Liu J, Zhang MF. Correlation of occupational stress, coping style and subjective well-being of health workes. China J Health Psychol. 2019;27:1627-30.

23. Siegrist J, Wege N, Pühlhofer F, Wahrendorf M. A short generic measure of work stress in the era of globalization: effort reward imbalance. Int Arch Occup Environ Health. 2009;82(8):1005-13. https://doi.org/10.1007/s00420008-0384-3.

24. Siegrist J, Starke D, Chandola T, Godin I, Marmot M, Niedhammer I, et al. The measurement of effort-reward imbalance at work: European comparisons. Soc Sci Med. 2004;58(8):1483-99. https://doi.org/10.1016/502 77-9536(03)00351-4
25. Bethge M, Radoschewski FM, Gutenbrunner C. Effort-reward imbalance and work ability: cross-sectional and longitudinal findings from the second German Sociomedical panel of employees. BMC Public Health. 2012;12(1): 875-83. https://doi.org/10.1186/1471-2458-12-875.

26. Magnavita N. Work-related psychological injury is associated with metabolic syndrome components in apparently healthy workers. PLoS One. 2015;10(6): e0130944. https://doi.org/10.1371/journal.pone.0130944.

27. Garbarino S, Magnavita N. Work stress and metabolic syndrome in police officers. A prospective study. PLoS One. 2015;10(12):e0144318.

28. Magnavita N, Fileni A. Work stress and metabolic syndrome in radiologists: first evidence. Radiol Med. 2014;119(2):142-8. https://doi.org/10.1007/s1154 7-013-0329-0.

29. Theorell T. On effort-reward imbalance and depression. Scand J Work Environ Health. 2017;43(4):291-3. https://doi.org/10.5271/sjweh.3642.

30. Rugulies R, Aust B, Madsen IE. Effort-reward imbalance at work and risk of depressive disorders. A systematic review and meta-analysis of prospective cohort studies. Scand J Work Environ Health. 2017;43(4):294-306. https://doi. org/10.5271/sjweh.3632.

31. Li L, Zhou H, Liu XY, Fan LH, Duan XJ, Zhao W, et al. Effects of the work stress on the job satisfaction of community health staff in Harbin. Med Soc. 2014;27(78-79):85.

32. Wang C, Ding X, Niu D, Li Y, Fu H. Moderating effect of psychological coherence on loss of health productivity caused by effort-reward imbalance. Occup Health. 2019;35(594-97):602.

33. Li J, Yang W, Cheng Y, Siegrist J, Cho Sl. Effort-reward imbalance at work and job dissatisfaction in Chinese health care workers: a validation study. Int Arch Occup Environ Health. 2005;78(3):198-204. https://doi.org/10.1007/ s00420-004-0581-7.

34. Buysse DJ, Reynolds CF 3rd, Monk TH, Berman SR, Kupfer DJ. The Pittsburgh sleep quality index: a new instrument for psychiatric practice and research. Psychiatry Res. 1989;28(2):193-213. https://doi.org/10.1016/0165-1781 (89)90047-4.

35. Liu X, Tang M, Hu L, Wang AZ, Wu HX, Zhao GF, et al. Study of the reliability and validity of the Pittsburgh Sleep Quality Index. Chin J Psychiatr. 1996;29:103-7.

36. Netterstrom B, Hansen AM. Outsourcing and stress physiological effects on bus drivers. Stress Health. 2000;16:149-60.

37. Hinsch DM, Spanier K, Radoschewski FM, Bethge M. Associations between overcommitment, effort-reward imbalance and mental health: findings from a longitudinal study. Int Arch Occup Environ Health. 2019;92(Suppl 5): $559-67$.

38. Wu H, Liu L, Wang Y, Gao F, Zhao X, Wang L. Factors associated with burnout among Chinese hospital doctors: a cross-sectional study. BMC Public Health. 2013;13(1):786. https://doi.org/10.1186/1471-2458-13-786.

39. Lu L, Dong M, Wang SB, Zhang L, Chee HN, Gabor SU, et al. Prevalence of workplace violence against health-care professionals in China: a comprehensive meta-analysis of observational surveys. Trauma Violence Abuse. 2020;21(3):498-509. https://doi.org/10.1177/1524838018774429.

40. Yu-Tao X, Yu J, Yu W, Qinge Z, Ling Z, Teris C. Tribute to health workers in China: a group of respectable population during the outbreak of the COVID-19. Int J Biol Sci. 2020;16:1739-40.

41. Kim G, Min B, Jung J, Paek D, Cho SI. The association of relational and organizational job stress factors with : analysis of the 3rd Korean working conditions survey (2011). Ann Occup Environ Med. 2016;28(1):46. https://doi. org/10.1186/s40557-016-0131-2.

42. Zhang YM. Analysis of organizational loyalty and related factors of grassroots medical staff in a development zone in Hangzhou [M.D]. Zhejiang University. 2015.

43. Chen SL, Cheng C, Mao JF, et al. Effort-reward imbalance, perceived organizational support and depression symptoms among health workers in Jiangsu Province. Chin J Health Stat. 2019;36:44-8.

44. Zhang J, Gu Q, Dai HF, Zhu JF, Gao Z, He J. Occupational stress and influencing factors among community medical personnel in qingpu district of Shanghai. Occup Health Emerg Rescue. 2019;37:402-5.

45. Klein J, Grosse Frie K, Blum K, von dem Knesebeck O. Psychosocial stress at work and perceived quality of care among clinicians in surgery. BMC Health Serv Res. 2011;11(1):109. https://doi.org/10.1186/1472-6963-11-109.

46. Ota A, Mase J, Howteerakul N, Rajatanun T, Suwannapong N, Yatsuya H, et al. The effort-reward imbalance work-stress model and daytime salivary cortisol and dehydroepiandrosterone (DHEA) among Japanese women. Sci Rep. 2014;4:6402. 
47. Heo YS, Chang SJ, Park SG, Leem JH, Jeon SH, Lee BJ, et al. Association between workplace risk factor exposure and sleep disturbance:analysis of the 2nd Korean working conditions survey. Ann Occup Environ Med. 2013; 25:1-11.

48. Jean-Pierre N. Jailed resources: conservation of resources theory as applied to burnout among prison guards. J Organ Behav. 2007;28:21-42.

49. Solis-Soto MT, Schön A, Parra M, Radon K. Associations between effortreward imbalance and health indicators among school teachers in Chuquisaca, Bolivia: a cross-sectional study. BMJ Open. 2019;9:e025121.

50. Ge JJ, He J, Liu Y, Zhang JY, Pan JP, Zhang XL, et al. Effects of effort-reward imbalance, job satisfaction, and work engagement on self-rated health among healthcare workers. BMC Public Health. 2021;21(1):195. https://doi. org/10.1186/s12889-021-10233-w.

51. Von dem Knesebeck O, Klein J, Grosse Frie K, Blum K, Siegrist J. Psychosocial stress among hospital doctors in surgical fields: results of a nationwide survey in Germany. Dtsch Arztebl Int. 2010;107:248-53.

52. Feleke SA, Mulatu MA, Yesmaw YS. Medication administration error: magnitude and associated factors among nurses in Ethiopia. BMC Nurs. 2015;14(1):53. https://doi.org/10.1186/s12912-015-0099-1.

53. Li J, Yang W, Cheng Y, Siegrist J, Cho Sl. Effort-reward imbalance at work and job dissatisfaction in Chinese healthcare workers: a validation study. Int Arch Occup Environ Health. 2005;78(3):198-204. https://doi.org/10.1007/ s00420-004-0581-7.

54. Loerbroks A, Weig M, Li J, Angerer P. Effort-reward imbalance and perceived quality of patient care: a cross-sectional study among physicians in Germany. BMC Public Health. 2016;16:342.

55. Satuf C, Monteiro S, Pereira H, Esgalhado G, Marina Afonso R, Loureiro M. The protective effect of job satisfaction in health, happiness, well-being and self-esteem. Int J Occup Saf Ergon. 2018;24(2):181-9. https://doi.org/10.1 080/10803548.2016.1216365.

56. Keser A, Li J, Siegrist J. Examining effort-reward imbalance and depressive symptoms among Turkish University workers. Workplace Health Staff. 2019, 67(3):131-6. https://doi.org/10.1177/2165079918807227.

57. Hanson LL, Åkerstedt T, Na Swall K, Leineweber C, Theorell T, Westerlund H. Cross-lagged relation ships between workplace demands, control, support, and sleep problemss. Sleep. 2011;34(10):1403-10. https://doi.org/10.5665/ SLEEP.1288.

\section{Publisher's Note}

Springer Nature remains neutral with regard to jurisdictional claims in published maps and institutional affiliations.

Ready to submit your research? Choose BMC and benefit from:

- fast, convenient online submission

- thorough peer review by experienced researchers in your field

- rapid publication on acceptance

- support for research data, including large and complex data types

- gold Open Access which fosters wider collaboration and increased citations

- maximum visibility for your research: over $100 \mathrm{M}$ website views per year

At $\mathrm{BMC}$, research is always in progress.

Learn more biomedcentral.com/submissions 